\section{THU0390 GENETIC STUDY OF MEDICAL IMAGE PROGRESSION IN A CHINESE AS POPULATION FOR SIX MONTHS' FOLLOW-UP}

LIU JING ${ }^{1}$, Qi Zhu' ${ }^{2}$, Weilin $\mathrm{Pu}^{1}$, Dongyi He ${ }^{2}$, Hejian Zou ${ }^{3}$, Xiaodong Zhou ${ }^{4}$, John D Reveille ${ }^{4}$, Jiucun Wang ${ }^{1} .{ }^{1}$ Fudan University, State Key Laboratory of Genetic Engineering, Collaborative Innovation Center for Genetics and Development, School of Life Sciences, Shanghai, China; ${ }^{2}$ Guanghua Integrative Medicine Hospital, Shanghai, China; ${ }^{3}$ Fudan University, Huashan Hospital, Shanghai, China; ${ }^{4}$ The University of Texas Health Science Center at Houston, Houston, United States of America

Background: Genetic factors accounts for about $90 \%$ pathogenesis of ankylosing spondylitis (AS), and may predict the disease progression. MRI is an important tool for evaluating disease progression and assessing treatment response in patients with AS.

Objectives: This study aims to define correlation between AS-associated genetic variations and MRI scores of AS patients in Chinese population. Methods: A total of 62 AS patients treated with TNF blockers from Guanghua medical center (Shanghai, China) were recruited in this study. All of AS patients were evaluated for disease progression with MRI (SPARCC) [1-3]. Measures of inflammation (bone marrow edema (BME) of sacroiliac joints (SIJ) and spine) and structural damage (fat metaplasia, erosion, backfill and ankylosis of SIJ) were recorded at baseline and six months' follow-up. The changes of MRI scores were defined as the score of six months' follow-up minus that of baseline. All of patients were examined with whole exon sequencing for genetic polymorphisms. Logistic regression analysis was performed and genetic variants with $\mathrm{p}<1 \mathrm{E}-4$ were considered as significant.

Results: The results showed that seven genetic variants significantly enriched in extracellular matrix pathways were associated with the changes of BME score of SIJ and spine. Four genetic variants regulating bone homeostasis, such as $A B C A 4$, were significantly associated with the changes of fat metaplasia. Twelve variants were associated with the changes of erosion, one of which regulated expression of FBF1 according to GTEx database $(\beta / p$-value $=-5.0 / 1 \cdot 1 \mathrm{E}-5)$. Mouse with Fbf1 knockout showed abnormality in insulin metabolism and skeleton (MGl database). Genetic variants of the adipose related gene (CTBP2) and bone related genes (RGMA, BMP8A) were associated with the changes of backfill. In addition, genetic variants of FAT4 was associated with the changes of ankylosis $(\beta / p$-value $=6.8 / 1.4 \mathrm{E}-8)$. Mutation of FAT4 caused two bone related diseases and mouse with Fat4 knockout showed severe abnormality of skeleton (MGI database).

Conclusion: Overall, the results suggested that the polymorphisms of genes involved in extracellular matrix were associated with BME, and genetic variants involved in adipose and bone metabolism were associated with structural damage in AS patients.

\section{REFERENCES:}

[1] Maksymowych WP, Inman RD, Salonen D, Dhillon SS, Krishnananthan R, Stone M, et al. Spondyloarthritis Research Consortium of Canada magnetic resonance imaging index for assessment of spinal inflammation in ankylosing spondylitis. Arthritis and rheumatism. 2005 Aug 15; 53(4):502509.

[2] Maksymowych WP, Inman RD, Salonen D, Dhillon SS, Williams M, Stone $M$, et al. Spondyloarthritis research Consortium of Canada magnetic resonance imaging index for assessment of sacroiliac joint inflammation in ankylosing spondylitis. Arthritis and rheumatism. 2005 Oct 15; 53(5):703709.

[3] Maksymowych WP, Wichuk S, Chiowchanwisawakit P, Lambert RG, Pedersen SJ. Development and preliminary validation of the spondyloarthritis research consortium of Canada magnetic resonance imaging sacroiliac joint structural score. The Journal of rheumatology. 2015 Jan; 42(1):79-86.

Disclosure of Interests: JING LIU: None declared, Qi Zhu: None declared, Weilin Pu: None declared, Dongyi He: None declared, Hejian Zou: None declared, Xiaodong Zhou: None declared, John D Reveille Grant/research support from: Janssen Research \& Development, LLC, Jiucun Wang: None declared

DOI: 10.1136/annrheumdis-2019-eular.2916

\section{THU0391 \\ COMPARISON OF CHARACTERISTICS AND BURDEN OF DISEASE IN PATIENTS WITH RADIOGRAPHIC AND NON-RADIOGRAPHIC AXIAL SPONDYLOARTHRITIS: A SYSTEMATIC LITERATURE REVIEW AND META- ANALYSIS}

Clementina López-Medina ${ }^{1,2}$, Sofia Ramiro ${ }^{3,4}$, Désirée van der Heijde ${ }^{3}$, Maxime Dougados ${ }^{1}$, Anna Moltó'. ' ${ }^{1}$ Cochin Hospital, Rheumatology, Paris, France; ${ }^{2}$ Universidad de Córdoba, Córdoba, Spain; ${ }^{3}$ LUMC, Leiden, Netherlands;

${ }^{4}$ Zuyderland MC, Heerlen, Netherlands

Background: In 2009, the ASAS criteria allowed to classify patients with radiographic ( $\mathrm{r}-\mathrm{axSpA})$ and non-radiographic (nr-axSpA) axial Spondyloarthritis (axSpA), and enhanced the concept of axSpA as a whole disease with different phenotypic presentations. However, some have claimed that the burden of $\mathrm{r}$-axSpA and nr-axSpA is so different that they should be considered as different forms of the same disease.

Objectives: To compare the characteristics, burden of disease and treatment effect in patients with $r$-axSpA and $n r-a x S p A$.

Methods: A systematic literature review until October 2018 was performed using PubMed, EMBASE and Cochrane databases. The PICO approach was used to formulate the research questions: P ( $r$-axSpA patients), I (no intervention/drugs (only for the treatment effect evaluation), C (nr-axSpA patients), $\mathrm{O}$ (clinical presentation, disease activity, structural damage, function, quality of life, mobility, treatment modalities and treatment effect). Only observational studies and Randomized Controlled Trials (RCT) published after 2009 (year of publication of the ASAS criteria) were included. For the evaluation of the treatment effect, only RCT were considered. Risk of bias was evaluated on each manuscript with the Cochrane Risk of Bias tool for RCT and Hayden tool for observational studies. Pooled analysis was performed (Standardized Means Differences (SMD) and Relative Risk (RR) for continuous and binary variables, respectively) with a random effects model after evaluation of the heterogeneity of the studies. Results: A total of 60 studies out of 787 references were included. Clinical presentation, disease activity, burden of disease (function, quality of life and mobility), treatment and treatment effect were evaluated in 54 $(90.0 \%), 40(67.7 \%), 37(61.7 \%), 18(30.0 \%)$ and in $9(15.0 \%)$ manuscripts, respectively. Only 3 cross-sectional studies were classified as high risk of bias. Pooled results concerning continuous and binary variables are represented in tables 1 and 2. Only two RCTs (Etanercept vs. Sulfasalzine and Certolizumab vs. Placebo) directly compared the treatment effect between both groups, and none of them showed differences regarding ASAS partial remission, ASDAS major improvement and ASAS 40.

Conclusion: Published data suggest that $r$-axSpA and nr-axSpA patients share a similar clinical presentation except for peripheral manifestations (which are more prevalent among $\mathrm{nr}$-axSpA), males and smokers (which are more frequent among $r$-axSpa). Disease activity and burden of disease are identical in both groups, except mobility, which is poorer among $\mathrm{r}$-axSpA. The treatment effect was similar in both groups.

\section{Abstract THU0391 -Table 1}

Table 1. Pooled results for clinical presentation, disease activity, burden of disease and treatment for continuous variables in r-axSpA vs. nr-axSPA patients.

\begin{tabular}{|c|c|c|c|}
\hline & $\begin{array}{c}r \text {-axSpA } \\
\text { Pooled mean }(95 \% \mathrm{Cl})\end{array}$ & $\begin{array}{c}\mathrm{nr} \text {-axSpA } \\
\text { Pooled mean }(95 \% \mathrm{Cl}) \\
\end{array}$ & SMD (95\%Cl)* \\
\hline \multicolumn{4}{|l|}{ Clinical presentation } \\
\hline Age at symptom onset & $26.3(24.8$ to 27.9$)$ & $27.8(26.2$ to 29.4$)$ & $-0.11(-0.2$ to 0.01$)$ \\
\hline Time to diagnosis & 6.1 (5.5 to 6.6$)$ & $4.2(2.2$ to 6.2$)$ & 0.31 (0.1 to 0.5$)$ \\
\hline \multicolumn{4}{|l|}{ MRI inflammation } \\
\hline SPARCC total SIJ & $7.7(5.4$ to 10.1$)$ & $7.2(5.9$ to 8.6$)$ & $0.31(-0.3$ to 0.9$)$ \\
\hline Berlin activity score spine & $5.5(1.6$ to 9.4$)$ & $2.9(-0.2$ to 5.9$)$ & $1.87(-0.5$ to 0.6$)$ \\
\hline \multicolumn{4}{|l|}{ Structural damage } \\
\hline mSASSS & 8.1 (5.3 to 10.9$)$ & $2.7(1.7$ to 3.6$)$ & $0.52(0.4$ to 0.6$)$ \\
\hline \multicolumn{4}{|l|}{ Disease activity } \\
\hline BASDAI & $4.6(4.3$ to 4.9$)$ & $4.6(4.3$ to 5.0$)$ & $-0.03(-0.1$ to 0.0$)$ \\
\hline CRP & $9.3(7.9-10.6)$ & $6.2(5.2$ to 7.3$)$ & $0.29(0.2$ to 0.4$)$ \\
\hline ASDAS-CRP & $2.7(2.4-3.0)$ & $2.6(2.3$ to 2.8$)$ & $0.11(0.0$ to 0.2$)$ \\
\hline \multicolumn{4}{|l|}{ Function } \\
\hline BASFI & $3.4(3.1$ to 3.7$)$ & $3.0(2.7$ to 3.3$)$ & 0.19 (0.1 to 0.3$)$ \\
\hline HAQ-S & $0.6(0.5$ to 0.8$)$ & $0.6(0.5$ to 0.7$)$ & $0.06(-0.1$ to 0.2$)$ \\
\hline \multicolumn{4}{|l|}{ Quality of life } \\
\hline SF36-MCS & 48.5 (46.5 to 50.6$)$ & $48.2(44.1$ to 52.3$)$ & $0.02(-0.1$ to 0.1$)$ \\
\hline SF36-PCS & 40.6 (37.0 to 44.3$)$ & $41.9(37.2$ to 46.7$)$ & $-0.04(-0.2$ to 0.1$)$ \\
\hline \multicolumn{4}{|l|}{ Mobility } \\
\hline BASMI & 2.8 (2.3 to 3.3$)$ & $1.6(1.3$ to 1.9$)$ & $0.69(0.5$ to 0.9$)$ \\
\hline
\end{tabular}


Abstract THU0391 -Table 2.

\begin{tabular}{|c|c|c|c|}
\hline & $\begin{array}{c}\text { r-axSpA } \\
\text { Pooled percentage } \\
(95 \% \mathrm{CI})\end{array}$ & $\begin{array}{c}\text { nr-axSpA } \\
\text { Pooled percentage } \\
(95 \% \mathrm{Cl})\end{array}$ & RR $(95 \% \mathrm{Cl})$ \\
\hline \multicolumn{4}{|l|}{ Clinical presentation } \\
\hline Sex (male) & $69.8(66.2-72.8)$ & $53.6(49.0-58.1)$ & $1.30(1.2-1.4)$ \\
\hline Smoker & $37.7(26.9-50.0)$ & $31.1(21.6-42.6)$ & $1.18(1.1-1.3)$ \\
\hline HLAB27 positive & $76.7(71.6-81.1)$ & $71.9(66.7-76.6)$ & $1.04(0.9-1.1)$ \\
\hline Good NSAIDs response & $68.5(56.0-78.8)$ & $61.7(53.3-69.4)$ & $1.09(0.9-1.1)$ \\
\hline Peripheral arthritis & $32.8(27.6-38.5)$ & $35.2(28.9-41.9)$ & $0.87(0.8-0.9)$ \\
\hline Dactylitis & $5.6(3.9-7.9)$ & $7.6(5.5-10.5)$ & $0.64(0.5-0.8)$ \\
\hline Any enthesitis & $23.0(14.0-35.4)$ & $30.1(22.0-39.7)$ & $0.84(0.7-0.9)$ \\
\hline Uveitis & $18.0(13.4-23.8)$ & $14.3(12.0-16.9)$ & $1.31(1.1-1.6)$ \\
\hline Psoriasis & $8.5(5.6-12.8)$ & $9.3(7.4-11.7)$ & $0.98(0.8-1.1)$ \\
\hline IBD & $6.5(5.2-8.2)$ & $5.6(4.0-7.9)$ & $1.04(0.9-1.3)$ \\
\hline \multicolumn{4}{|l|}{ MRI inflammation } \\
\hline $\begin{array}{l}\text { Patients with positive MRI-SIJ } \\
\text { ASAS definition }\end{array}$ & $45.8(18.7-75.7)$ & $71.5(66.9-75.8)$ & $0.57(0.3-1.1)$ \\
\hline \multicolumn{4}{|l|}{ Structural damage } \\
\hline Patients with erosion MRI-SIJ & $70.8(41.8-89.1)$ & $41.0(19.0-67.3)$ & $1.8(1.1-3.0)$ \\
\hline $\begin{array}{l}\text { Patients with fatty lesions } \\
\text { MRI-SIJ }\end{array}$ & $79.4(56.1-92.1)$ & $51.5(28.4-74.0)$ & $1.4(1.2-1.7)$ \\
\hline \multicolumn{4}{|l|}{ Treatment } \\
\hline NSAIDs & $73.5(63.1-81.8)$ & $69.1(55.5-80.0)$ & $1.04(0.9-1.1)$ \\
\hline csDMARDs & $29.3(20.5-39.9)$ & $28.5(21.9-36.1)$ & $1.04(0.8-1.3)$ \\
\hline bDMARL & $28.7(19.7-39.7)$ & $26.2(26.1-39.6)$ & $1.08(0.9-1.3)$ \\
\hline
\end{tabular}

Disclosure of Interests: Clementina López-Medina: None declared, Sofia Ramiro Grant/research support from: MSD, Consultant for: AbbVie, Lilly, MSD, Novartis, Pfizer, Sanofi, Speakers bureau: AbbVie, Lilly, MSD, Novartis, Pfizer, Sanofi, Désirée van der Heijde Consultant for: AbbVie, Amgen, Astellas, AstraZeneca, Bristol-Myers Squibb, Boehringer Ingelheim, Celgene, Daiichi, Eli-Lilly, Galapagos, Gilead, GlaxoSmithKline, Janssen, Merck, Novartis, Pfizer, Regeneron, Roche, Sanofi, Takeda, Union Chimique Belge, maxime dougados Grant/research support from: Eli Lilly and Company, Pfizer, AbbVie, and UCB Pharma, Consultant for: Eli Lilly and Company, Pfizer, AbbVie, and UCB Pharma, Anna Moltó: None declared DOI: 10.1136/annrheumdis-2019-eular.3542

\section{THU0392 DESCRIPTIONAND PREVALENCE: OF SPONDYLOARTHRITIS IN UNSELECTED PATIENTS WITH PSORIASIS, ACUTE ANTERIOR UVEITIS, AND INFLAMMATORY BOWEL DISEASE PRESENTING WITH UNDIAGNOSED BACK PAIN}

Walter P Maksymowych ${ }^{1,2}$, Raj Carmona ${ }^{3}$, James Yeung ${ }^{4}$, Jon Chan ${ }^{5}$, Liam Martin $^{6}$, Sibel Aydin ${ }^{7}$, Dianne Mosher ${ }^{6}$, Ariel Masetto ${ }^{8}$, Stephanie Keeling ${ }^{1}$, Olga Ziouzina ${ }^{6}$, Sherry Rohekar ${ }^{9}$, Joel Paschke ${ }^{2}$, Amanda Carapellucci ${ }^{2}$, Robert G Lambert ${ }^{1} .{ }^{1}$ University of Alberta, Edmonton, Canada; ${ }^{2}$ CaRE Arthritis, Edmonton, Canada; ${ }^{3}$ McMaster University, Hamilton, Canada; ${ }^{4}$ James Yeung Rheumatology, Vancouver, Canada; ${ }^{5}$ Artus Health Center, Vancouver, Canada; ${ }^{6}$ University of Calgary, Calgary, Canada; ${ }^{7}$ University of Ottawa, Ottawa, Canada ${ }^{8}$ University of Sherbrooke, Sherbrooke, Canada; ${ }^{9}$ Lawson Health Research Institute, London, Canada

Background: There is limited prospective data as to the frequency of axial spondyloarthritis $(\mathrm{axSpA})$ in unselected patients referred to rheumatologists with undiagnosed back pain. It is also unclear which clinical features discriminate between axSpA and non-specific causes of back pain that might inform the development of a screening strategy.

Objectives: To determine the prevalence of axSpA in unselected patients referred with undiagnosed back pain presenting with AAU, psoriasis, or colitis and determine which clinical characteristics define patients with axSpA.

Methods: The multicenter Screening for Axial Spondyloarthritis in Psoriasis, Iritis, and Colitis (SASPIC) Study is aimed at facilitating early detection of axial SpA. First and last patients were recruited on February 2013 and March 2018, respectively. Consecutive patients $\leq 45$ years of age with $\geq 3$ months undiagnosed back pain with any one of psoriasis, $\mathrm{AAU}$, or colitis had routine clinical evaluation by a rheumatologist for axial SpA and MRI evaluation ordered per rheumatologist decision. Differences in clinical characteristics between those who were diagnosed as axSpA or non-specific back pain were analyzed using chi-squared and ttests.
Results: A total of 246 patients were recruited, $47.6 \%$ were diagnosed with axSpA, and these included $68.5 \%$ of B27 positive patients (Table 1). Diagnosis of axSpA was established in $45.7 \%, 61.6 \%$, and $40.2 \%$ of patients, while ASAS classification criteria were met by $26.1 \%, 71.2 \%$, and $27.6 \%$ of patients with psoriasis, AAU, and IBD, respectively. Features of inflammatory back pain, male gender, and B27 positivity, but not physical measures discriminated axSpA from other causes of back pain (Table 2).

Abstract THU0392 -Table 1

\begin{tabular}{lccc}
\hline & Psoriasis & AAU & IBD \\
\hline Total number (\%) & $46(18.7 \%)$ & $73(29.7 \%)$ & $127(51.6 \%)$ \\
Age, mean (SD) years & $36.7(6.0)$ & $34.0(5.8)$ & $34.0(7.3)$ \\
Males, N (\%) & $24(52.2 \%)$ & $41(56.2 \%)$ & $64(50.4 \%)$ \\
Symptom Duration, mean (SD) years & $7.7(7.7)$ & $8.7(6.7)$ & $6.3(5.9)$ \\
B27+, N (\%) & $10(21.7 \%)$ & $51(69.9 \%)$ & $28(22.0 \%)$ \\
Family history of SpA, N (\%) & $15(32.6 \%)$ & $15(20.5 \%)$ & $20(15.7 \%)$ \\
Enthesitis, N (\%) & $15(32.6 \%)$ & $13(17.8 \%)$ & $39(30.7 \%)$ \\
Peripheral arthritis, N (\%) & $13(28.3 \%)$ & $2(2.7 \%)$ & $5(3.9 \%)$ \\
Dactylitis, N (\%) & $4(8.7 \%)$ & $2(2.7 \%)$ & $3(2.4 \%)$ \\
Radiographic sacroiliitis,\% & $6.5 \%$ & $23.3 \%$ & $10.2 \%$ \\
Axial SpA rheumatologist diagnosis,\% & $45.7 \%$ & $61.6 \%$ & $40.2 \%$ \\
Axial SpA diagnosis and B27+,\% & $15.2 \%$ & $52.1 \%$ & $12.6 \%$ \\
Meets ASAS criteria,\% & $26.1 \%$ & $71.2 \%$ & $27.6 \%$ \\
\hline
\end{tabular}

Abstract THU0392 -Table 2.

\begin{tabular}{lccc}
\hline Demographics & $\begin{array}{c}\text { axSpA YES } \\
(\mathbf{n = 1 1 7},\end{array}$ & $\begin{array}{c}\text { Not axSpA } \\
(\mathbf{n = 1 2 9 ,}\end{array}$ & P value \\
& $\mathbf{4 7 . 6 \% )}$ & $\mathbf{5 2 . 4 \% )}$ & \\
\hline Male, N (\%) & $72(61.5 \%)$ & $57(44.2 \%)$ & 0.006 \\
Mean (SD) age, years & $33.7(6.7)$ & $35.2(6.7)$ & $\mathrm{ns}$ \\
Inflammatory Back Pain Yes, N (\%) & $102(87.2 \%)$ & $72(55.8 \%)$ & $<0.00001$ \\
Duration stiffness > 60 mins, N (\%) & $57(48.7 \%)$ & $30(23.3 \%)$ & 0.001 \\
Nocturnal awakening 2nd half of night, N (\%) & $72(61.5 \%)$ & $51(39.5 \%)$ & 0.001 \\
Alternating buttock pain, N (\%) & $53(45.3 \%)$ & $21(16.3 \%)$ & $<0.00001$ \\
Improvement with exercise but not rest, N & $77(65.8 \%)$ & $48(37.2 \%)$ & $<0.00001$ \\
(\%) & & & \\
Respond to NSAID within 48 hrs, N (\%) & $58(49.6 \%)$ & $59(45.7 \%)$ & $\mathrm{ns}$ \\
Family history of SpA, N (\%) & $22(18.8 \%)$ & $28(21.7 \%)$ & $\mathrm{ns}$ \\
B27 positive & $61(52.1 \%)$ & $28(21.7 \%)$ & $<0.00001$ \\
Elevated CRP (> 6.0mg/L) & $43(36.8 \%)$ & $32(24.8 \%)$ & 0.042 \\
Radiographic sacroiliitis, N (\%), local readers & $54(46.2 \%)$ & $7(5.4 \%)$ & $<0.00001$ \\
\hline
\end{tabular}

Conclusion: Patients with extra-articular manifestations and undiagnosed back pain have a high prevalence of axSpA and referral to a rheumatologist should constitute standard of care, especially if B27 positive.

Disclosure of Interests: Walter P Maksymowych Grant/research support from: AbbVie, Pfizer, Janssen, Novartis, Consultant for: AbbVie, Eli Lilly, Boehringer, Galapagos, Janssen, Novartis, Pfizer and UCB Pharma; Chief Medical Officer for Canadian Research and Education Arthritis, Raj Carmona Grant/research support from: Amgen, Abbvie, Jannsen, Consultant for: Amgen, Abbvie, BMS, El Lilly, Merck, Novartis, Jannsen, Takeda, UCB, James Yeung: None declared, Jon Chan Grant/research support from: Janssen, UCB, Novartis, Pfizer, Celgene, Consultant for: Amgen, Celgene, Eli Lilly, Janssen, Amgen, Abbvie, Novartis, Pfizer, UCB, Sandoz, Merck, Liam Martin: None declared, Sibel Aydin Consultan for: Abbvie, Celgene, UCB, Novartis, Jannsen, Sanofi, Dianne Mosher: None declared, Ariel Masetto Grant/research support from: Amgen, Sanofi, Consultant for: Sanofi, Pfizer, Bristol-Myers Squibb, Novartis, Boehringer Ingelheim, Speakers bureau: Novartis, Stephanie Keeling Consultant for: AbbVie. Pfizer, Eli Lily, Janssen, Amgen, Astrzeeneca, UCB., Olga Ziouzina: None declared, Sherry Rohekar Consultant for: Abbvie, Amgen, BMS, Celgene, Eli-Lilly, Janssen, Merck, Novartis, Pfizer, Roche, Sanofi, UCB, Joel Paschke: None declared, Amanda Carapellucci: None declared, Robert G Lambert Consultant for: Bioclinica, Parexel, Abbvie

[3] DOI: 10.1136/annrheumdis-2019-eular.6299 